\title{
The effect of withdrawal of dopaminergic medication on simple and choice reaction time and the use of advance information in Parkinson's disease
}

\author{
Marjan Jahanshahi, Richard G Brown, C David Marsden
}

\begin{abstract}
Eight patients with Parkinson's disease performed simple reaction time (SRT), uncued, partially and fully cued four choice (CRT) tasks. They were tested on two occasions; on their normal dose of dopaminergic medication and following withdrawal of such medication for an average of 14.4 hours. Disability as rated on the Webster scale was greater in the drug reduced state. Although RTs were generally slower when tested in the drug reduced state than when on medication, few differences emerged. Withdrawal of dopaminergic medication had no effect on unwarned SRT and unwarned and uncued CRT performance. Both on and off medication, the patients benefited from a warning signal presented before the imperative stimulus. In both medication states, the speeding up of RT was greatest with a warning signal presented $200 \mathrm{~ms}$ before $S 2$. When the imperative stimulus was unwarned, the temporal predictability of its occurrence speeded RT more when on medication than when off. Advance movement parameter information was used by patients to pre-programme responses both on and off medication. In both medication states, the fully cued CRT was the same as SRT only with the $3200 \mathrm{~ms}$ S1-S2 interval. Medication state had no effect on movement time or the number of errors. It is suggested that slowness in motor readiness and motor programming may not be specific to striatal dopamine deficiency but rather a nonspecific concomitant of brain damage.
\end{abstract}

$(\mathcal{F}$ Neurol Neurosurg Psychiatry 1992;55:1168-1176)

Council Human

Balance Unit,

Department of

Clinical Neurology,

Institute of Neurology,

National Hospital for

Neurology and

Neurosurgery, London

M Jahanshahi

R G Brown

C D Marsden

Correspondence to:

Dr M Jahanshahi, MRC

Human Movement and

Hospital for Neurology and

Neurosurgery, Queen

Squrosurgery, Queen

W'iN 3BG.

Received 26 June 1991

and in revised form

28 November 1991

Accepted 24 April 1992
A major question is whether the slowness of movements in Parkinson's disease relates to deficits in programming of motor responses. A number of studies have addressed this question by comparing performance of the patients on simple reaction time (SRT) or choice reaction time (CRT) tasks when tested on and off dopaminergic medication. The results of these studies are inconsistent. In seven studies, dopaminergic medication levels had no effect on SRT. ${ }^{3-9}$ In contrast, four studies ${ }^{1013}$ found that SRT was significantly reduced following administration of dopaminergic medication. Only three studies have examined the effects of dopaminergic medication on CRT, and of these, two suggest no effect, ${ }^{59}$ and one reported prolongation of CRT with decreasing levels of dopaminergic medication. ${ }^{7}$ In terms of the relative effects of dopaminergic medication on SRT and CRT, Girotti et $a l^{5}$ and Pullman et $a l^{9}$ reported that neither SRT or CRT are affected by dopamine levels, while Pullman et $a l^{7}$ found differential effects, with significant reduction of CRT but not SRT with increasing levodopa infusion levels.

Closer scrutiny reveals that despite the differences in statistical outcome amongst the studies, the means of both SRT and CRT were reduced following administration of dopaminergic medication in all the studies. The magnitude and direction of the effect of dopaminergic medication on RT, however, were variable between patients within these studies. For example, Teravainen and Calne ${ }^{10}$ found that administration of dopaminergic medication reduced SRT in seven of the 11 patients and prolonged it in three cases. Inconsistencies may be partly due to the level of dopaminergic medication. This was partly overcome in the two studies by Pullman et al ${ }^{79}$ which were carried out on the same controls and patients each tested at three levodopa infusion levels. The first study examined direction and the second study used amplitude of movements as the relevant movement parameter in the CRT task. Change in levodopa infusion level from low to mid to high produced no effect on SRT in both studies. In contrast, although increasing infusion levels resulted in a significant reduction of directional two-choice $\mathrm{RT}^{7}{ }^{7}$ it had no effect on choice of movements of different amplitude. ${ }^{9}$

In conclusion, there is no consensus across studies with regard to the effects of dopaminergic medication on either SRT or CRT. The aim of the present study was to examine the effects of withdrawing dopaminergic medication on 
SRT and CRT and on motor readiness and programming of movements in Parkinson's disease. The specific questions addressed were:

(1) Does withdrawal of dopaminergic medication produce differential effects on SRT and CRT?

(2) Does withdrawal of dopaminergic medication alter the effects of a warning signal on RT?

(3) Does withdrawal of dopaminergic medication alter the patients' ability to develop a general readiness to respond?

(4) Does withdrawal of dopaminergic medication alter the patients' ability to use advance movement parameter information to preprogramme responses?

Method
Design
Eight patients with Parkinson's disease per-
formed seven experimental conditions A-G
(see fig 1), which were variations of an SRT
and a four-choice CRT task. Testing was
conducted on two occasions, once when the
patients were on their normal drug regime and
on a second occasion after withdrawal of
dopaminergic medication.

Subjects

Eight patients with a clinical diagnosis of idiopathic Parkinson's disease took part in the study. The patients were volunteers recruited from a pool of patients seen at the Movement Disorders Clinic of the National Hospital for Neurology and Neurosurgery. The demographic and illness related information are presented in the table. The severity of Parkinson's disease was rated by an independent neurologist on the Webster symptom severity and clinical disability scale. ${ }^{14}$ The neurologist also classified the patients in terms of stage of illness on medication using the Hoehn and $\mathrm{Yahr}^{15}$ criteria. The Hoehn and Yahr and the Webster ratings showed that most patients were in the mid-stage of the disease with moderate symptoms. There was no evidence of severe depression or cognitive deficit as assessed on the Beck Depression Inventory ${ }^{16}$ and the Mini-mental State Examination ${ }^{17}$ (table).

All of the patients were on dopaminergic

Table Demographic and illness-related details of the Parkinson's disease patients and disease severity measures on and off medication

\begin{tabular}{|c|c|c|c|}
\hline & No. of patients & Percentage & Mean (SD) (years) \\
\hline $\begin{array}{l}\text { Male } \\
\text { Female } \\
\text { Right handed } \\
\text { Left handed } \\
\text { Age } \\
\text { Age of onset } \\
\text { Duration of illness } \\
\text { Hoehn and Yahr classification } \\
\text { I } \\
\text { II } \\
\text { III }\end{array}$ & $\begin{array}{l}5 \\
3 \\
6 \\
2\end{array}$ & $\begin{array}{l}62 \cdot 5 \\
37 \cdot 5 \\
75 \\
25\end{array}$ & $\begin{array}{c}61 \cdot 3(9 \cdot 7) \\
53 \cdot 0(10 \cdot 4) \text { range } 34-66 \\
8 \cdot 3 \quad(5 \cdot 8) \text { range } 1-19\end{array}$ \\
\hline $\begin{array}{l}\text { Mini Mental scores } \\
\text { Beck Depression Inventory } \\
\text { Webster rating }\end{array}$ & \multicolumn{2}{|c|}{$\begin{array}{l}\text { On medication mean }(S D) \\
28.9(0.99) \\
8.9(5 \cdot 5) \\
8.4(3.8)\end{array}$} & $\begin{array}{l}\text { Off medication mean }(S D) \\
29 \cdot 1(0.99) \\
6.6(3.0) \\
14.6(5.6)\end{array}$ \\
\hline
\end{tabular}

medication [average levodopa dose $650 \mathrm{mg}$ (SD $305.9 \mathrm{mg}$ ) with a peripheral decarboxylase inhibitor], and on the first occasion were tested while on their normal dosage of medication. In addition, two patients were taking anticholinergics, three were also on monoamineoxidase B inhibitors (selegeline/deprenyl), and three were taking amantadine.

On the second occasion, the patients were tested in a "drug reduced" state, when the first morning dose of medication had been omitted. The average time between taking the last dose of levodopa on the previous evening and start of testing was $14 \cdot 4$ hours (SD 2.2, range $11-17$ hours). This period of withdrawal of medication is sufficiently long to allow considerable reduction of dopamine levels and a marked deterioration in mobility as indicated by the Webster scores (table). The average interval between the first and second testing occasion was 2.8 months (range 2-3.5 months).

\section{Reaction time tasks}

A detailed description of the experimental tasks and procedures has been previously reported. ${ }^{18} \mathrm{~A}$ brief outline will be provided here. The response board had six circular buttons each $2.5 \mathrm{~cm}$ in diameter, arranged as a right and left column separated by $15 \mathrm{~cm}$. The two black central buttons were the "home" keys. There were two red response buttons $10 \mathrm{~cm}$ above the "home" keys, and, the same distance below, two green response buttons.

The movement pre-cueing technique with high stimulus-response compatibility was used. The subject sat in front of a visual display unit, and held down one or both of the black "home" keys with the index finger of the right, left or both hands, depending on the condition. This made a small fixation cross appear in the middle of the screen. After a variable delay (1-4 s), a pre-cue or warning signal (S1) was presented. In all conditions, the pre-cue or warning signal was one or more empty squares. The filling (becoming white on the black screen background) of the relevant square after an experimentally manipulated interval of 0,200 , 800,1600 or 3200 ms constituted the imperative stimulus (S2).

Examples from each experimental condition are depicted in fig 1 . The pre-cue or warning signal was either superimposed on the fixation point (SRT conditions) or was presented in different spatial locations relative to the fixation point (CRT conditions). Depending on the experimental condition, the empty square constituted a pre-cue or warning signal, or both. When operating as a pre-cue, the spatial location of the empty square(s) relative to the fixation point, provided either partial or complete information about the direction or the hand to be used, or both of the impending movement in different experimental conditions. When informative, the subject was instructed to use the information conveyed by the pre-cue to partially or fully prepare the movement before presentation of the imperative stimulus. The subject's task was to respond as quickly as possible to the imperative stimulus by releasing the "home" key and moving 


\begin{tabular}{|c|c|c|c|}
\hline \multirow{3}{*}{ a Intervals } & $\begin{array}{l}\text { Fixation } \\
\text { Point }\end{array}$ & $\begin{array}{l}\text { Precue/Warning } \\
\text { Signal (S1) }\end{array}$ & $\begin{array}{c}\text { Imperative } \\
\text { Stimulus (S2) }\end{array}$ \\
\hline & \llcorner & & 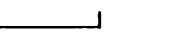 \\
\hline & & $\begin{array}{r}0,200 \\
32 C\end{array}$ & $\begin{array}{l}1600 \\
\text { cs }\end{array}$ \\
\hline
\end{tabular}

b The Reaction Time Tasks

SIMPLE RT

(Conditions A, B, G) †
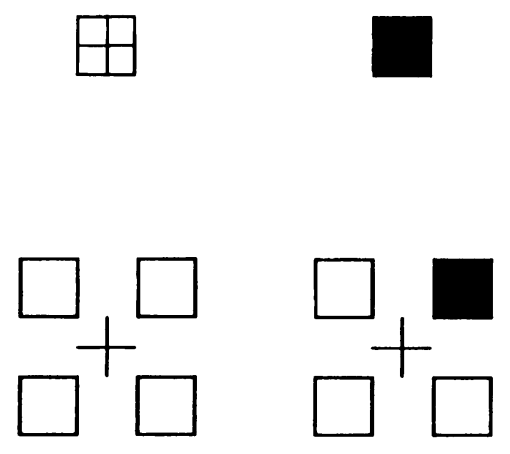

UNCUED CRT

(Condition C)

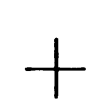

PARTIALLY CUED

CRT (HAND)

(Condition D)

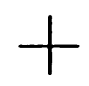

PARTIALLY CUED CRT (DIRECTION) (Condition E)
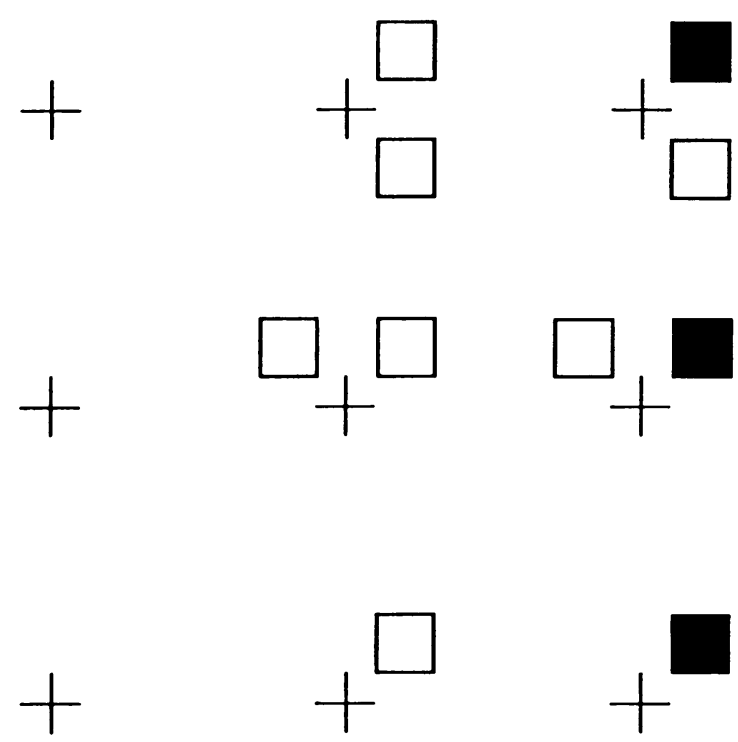

(Condition F)

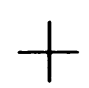

Figure 1 The intervals between appearance of the fixation point, the pre-cue or warning signal and the imperative stimulus are shown in (a). The stimulus display in the various experimental conditions is presented in (b).

to and pressing the relevant response key with the index finger. The screen cleared $0.5 \mathrm{~s}$ after a response was made, and the next trial was started when the subject depressed the "home" key.

Three types of invalid trials were recorded: anticipations (reaction time $100 \mathrm{~ms}$ or less), long responses (reaction time greater than $3 \mathrm{~s}$ ), and decision errors (wrong response key pressed in choice reaction time). Reaction time and movement time from these trials were eliminated. Trials were presented until the required number of valid trials ( 50 per hand in SRT, 75 in each CRT condition was achieved). Reaction time (RT) was measured as the time between presentation of the imperative stimulus and release of the "home" key. Movement time (MT) was the time taken to move from the "home" key to a response key.

Experimental conditions (see fig 1)

Simple reaction times In the SRT task, each block of trials involved the same response (for example, moving right index finger from "home" key to "response" key) to the same stimulus. Each subject performed four blocks of 50 trials (10 trials per interval), two blocks with each hand. The right upper and the left upper keys were the "response" keys respectively for SRT with the right and left hands. In each condition only the relevant "home" and "response" keys were exposed. Two versions of the SRT task were used: a random block SRT (condition A) and a fixed block SRT (condition B). In the "random block" condition, trials with each of the five S1-S2 intervals were randomly mixed in a block. The "fixed block" SRT was identical to condition A, except that the trials for each hand were organised into five sets of 10 consecutive trials for each of the S1-S2 intervals. Within each group, the order of the five S1-S2 intervals was counterbalanced. The order of right versus left hand performance was also counterbalanced across subjects in each group.

Choice reaction times The two movement parameters were hand (right versus left) and direction (up versus down). The response was fully or partially cued or uncued across the conditions. Each CRT condition consisted of a block of 75 trials, with 15 trials at each of the five S1-S2 intervals randomly mixed. An almost equal and randomly mixed number of right and left hand responses were incorporated.

In the uncued block (condition $\mathrm{C}$ ), four empty squares appeared on the screen to the left and right and above and below the fixation point. After the S1-S2 interval, one of the four squares filled, indicating the movement to be made. For partial cueing of hand (condition D), two empty squares appeared above and below the fixation point either to its left or right. After the S1-S2 interval, either the upper or lower square filled, and acted as the imperative stimulus. In condition $\mathrm{E}$, direction (up versus down) was partially precued by two empty squares which appeared to the left and right of the fixation point either above or below it. After the S1-S2 interval, the right or left square filled and indicated the exact response to be made. In the fully cued condition F, an empty square appeared on the screen in one of the four possible positions above or below, to the left or right of the fixation point. After the S1-S2 interval, the square filled, instructing the subject to move to the appropriate response key. In this condition, the subject knew the precise nature of the movement to be made before $\$ 2$.

Order of testing

All subjects performed the SRT conditions (A and B) first, followed by the four CRT conditions $(\mathrm{C}-\mathrm{F})$. The order of the four CRT conditions was counterbalanced. As a result of the fixed SRT then CRT order, any practice or fatigue effects would be expected to be greater in the conditions performed later. To assess fatigue or practice effects, the random block SRT condition was repeated at the end of the session (condition $\mathrm{G}$ ). 


\section{Results}

Given the within-subjects nature of the design, the data were analysed using paired $t$ tests, Wilcoxon paired test or repeated measures analysis of variance (ANOVA) as appropriate. Compared with the first occasion when they were tested on medication, the patients were more severely disabled when tested in the "drug reduced" state as indicated by the higher scores on the Webster scale on the second occasion compared with assessment on medication $(t=5.5, \mathrm{df}=7, \mathrm{p}=0.001)$. There were no differences in the BDI $(t=2 \cdot 2$, $\mathrm{df}=7, \mathrm{p}=0.07)$ and MMS $(t=0.48$, $\mathrm{df}=7, \mathrm{p}=0.65)$ scores of the patients when tested on and off medication.

When tested on medication, the SRT condition performed at the beginning of the session had a mean value of $408 \mathrm{~ms}$ across the five $\mathrm{S} 1-\mathrm{S} 2$ intervals compared with $450 \mathrm{~ms}$ at the end of the session. When tested in the drug reduced state, mean SRT values at the beginning and end of the session were 426 (SD 60) and 491 (SD 40) ms respectively. Therefore, across the five S1-S2 intervals, the SRT was slowed by $42 \mathrm{~ms}$ from the beginning to the end of the session when tested on medication, and by $65 \mathrm{~ms}$ when tested off medication. This fatigue effect was not different when the patients were tested on or off medication $(t=0.94, \mathrm{df}=7, \mathrm{p}=0.38)$.

\section{Unwarned SRT versus unwarned and uncued CRT}

To assess changes in "true" (unwarned and uncued) SRT and CRT, the RT data from the trials with no $\mathrm{S} 1$ (that is, $\mathrm{S} 1-\mathrm{S} 2$ interval of $0 \mathrm{~ms}$ ) on and off medication were compared (fig 2), using a two way (condition, medication status) repeated measures ANOVA. The main effect of condition (SRT versus CRT) was significant $(F(1,7)=35 \cdot 6, \quad \mathrm{p}=0.001)$, whereas the effect of medication status $(F(1,7)<1, \mathrm{p}=0.97)$ and the condition by medication status interaction were not $(F(1,7)=0.97, \mathrm{p}=0.36)$. The mean difference between SRT and CRT was $151 \mathrm{~ms}$ (SD $64)$ when tested on medication and $121 \mathrm{~ms}$ (SD $89 \mathrm{~ms}$ ) when tested in the drug reduced state.

Figure 2 The mean unwarned ( $S 1-S 2$ interval of $0 \mathrm{~ms}$ ) simple $R T$ (SRT) and the unwarned and uncued choice RT (CRT) conditions of the patients with Parkinson's disease on (unfilled symbols) and off (filled symbols) medication. The error bars are standard errors.

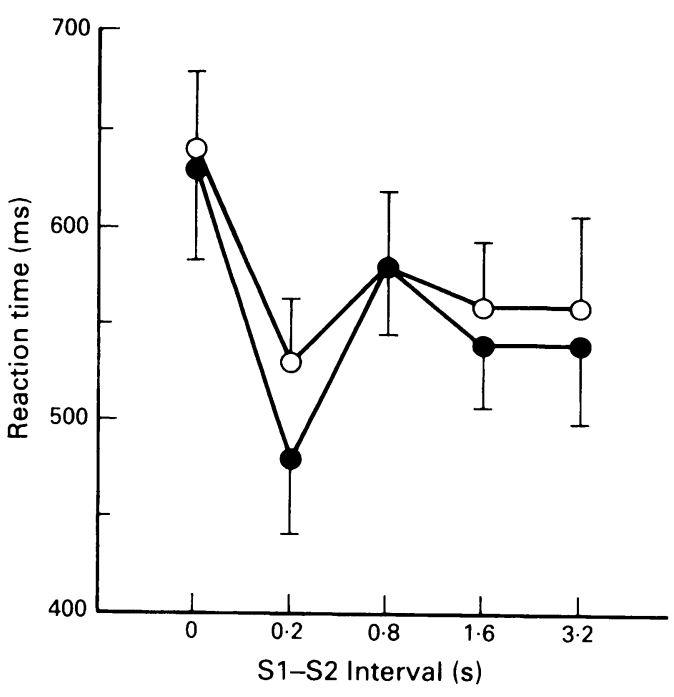

Figure 3 The mean RTs of the patients with Parkinson's disease on (unfilled symbols) and off medication (filled circles) across the five S1-S2 intervals in the uncued CRT condition. The error bars are standard errors.

\section{Warning signal}

The uncued CRT (condition C) was the only condition in which a warning signal was provided without the subject having advance information about the nature of the required response. To examine the facilitatory effects of a warning signal on RT, the S1-S2 interval of $0 \mathrm{~ms}$ (unwarned) was compared with the mean of the other four S1-S2 intervals (warned) in the uncued CRT condition. The relevant data are shown in fig 3. The main effect of warned or unwarned condition was significant $(F(1,7=37, \mathrm{p}=0.001)$, but not that for medication status $(F(1,7)=0 \cdot 18, \mathrm{p}=0.68)$ or the medication status by warned or unwarned condition interaction $(F(1,7)=0 \cdot 18$, $\mathrm{p}=0.68)$. Therefore, compared to the unwarned condition, a warning signal presented $200,800,1600$ or $3200 \mathrm{~ms}$ before S2 speeded up RT compared with no warning signal to the same degree in both the "on" and "off" states.

Both on and off medication, warned RT at each of the four S1-S2 intervals (200, 800, $1600,3200 \mathrm{~ms}$ ) was faster than unwarned RT $(\mathrm{p}<0.05)$. To determine the interval at which the warning signal produced the greatest reduction of RT, a number of post-hoc comparisons were carried out. Both on and off medication, a warning signal presented $200 \mathrm{~ms}$ before the imperative stimulus speeded RT significantly more $(p<0.01)$ than one occurring 800,1600 or $3200 \mathrm{~ms}$ before S2.

\section{Temporal expectancy}

The effect of temporal expectancy on RT was assessed by comparing the "random block" SRT condition A with the "fixed block" SRT condition $\mathrm{B}$ in which the warning signal occurred at a fixed interval (either 0, 200, 800, 1600 , or $3200 \mathrm{~ms}$ ) before S2 across 10 consecutive trials, which provided the opportunity for developing an anticipatory set. The mean times in the random and fixed block SRT conditions at each of the five S1-S2 intervals on and off medication are shown in fig 4 . A three way 


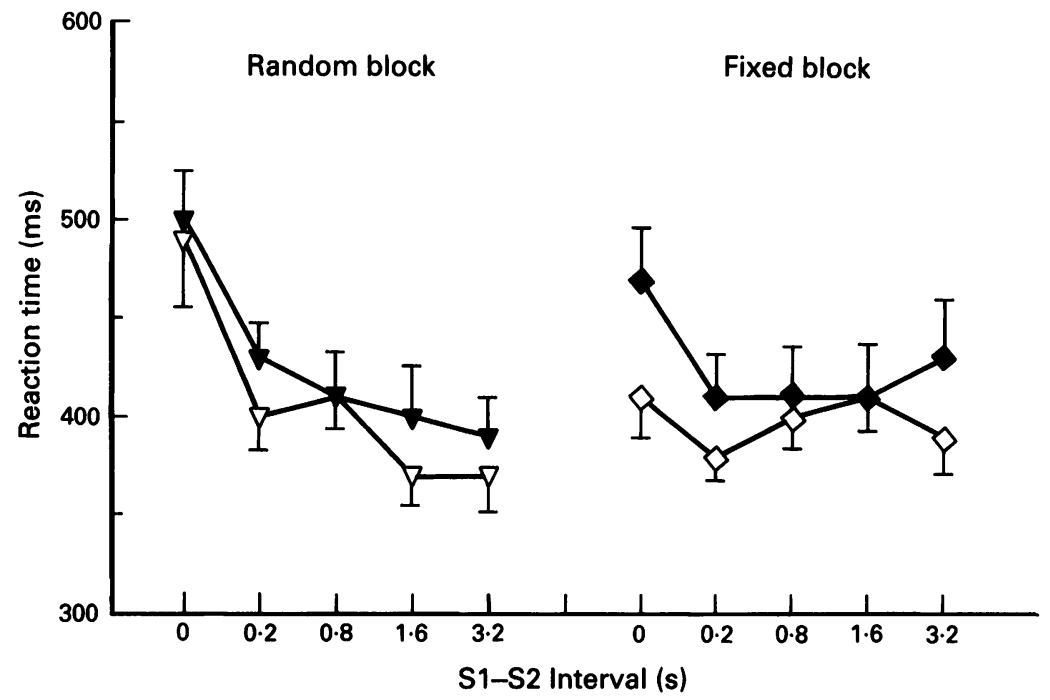

Figure 4 The mean RTs of the patients with Parkinson's disease across the five S1-S2 intervals in the fixed block (diamonds) and random block (inverted triangles) SRT conditions on (unfilled symbols) and off (filled symbols) medication. The error bars are standard errors. (condition, interval, medication status) repeated measures ANOVA was used to analyse the data. The effect of interval (multivariate $F(4,4)=6.9, \mathrm{p}=0.04$ ), the condition by interval interaction (multivariate $F(4,4)=25 \cdot 8, p=0 \cdot 004$ ), and the medication status by condition by interval interaction (univariate $F(4,28)=2 \cdot 8, \mathrm{p}=0.04$ ) were significant. None of the other effects were significant (condition: $F(1,7)=0.42$, $\mathrm{p}=0.54 ;$ medication status: $F(1,7)=1 \cdot 3$, $\mathrm{p}=0.29$; condition by medication status: $F(1,7)=0.27, \mathrm{p}=0.62$; medication status by interval: multivariate $F(4,4)=1 \cdot 3$, $\mathrm{p}=0.41$ ).

The significant three way interaction was explored further by examining medication and interval effects in the fixed and random block conditions separately. In the random block condition, only the main effect of interval was significant (multivariate $F(4,4=30 \cdot 6$, $\mathrm{p}=0.003$ ). In contrast, in the fixed block condition, in addition to the main effect of interval $(F(4,28=3 \cdot 8, \mathrm{p}=0.01)$, the interval by medication status interaction $(F(4,4)=9.4, \mathrm{p}=0.02)$ was also significant. This significant interaction within the fixed block condition resulted from the main effect of interval being significant in the "off" $(F(4,28)=7 \cdot 1, \mathrm{p}=0.001)$ but not the "on state" $(F(4,28=1 \cdot 2, \mathrm{p}=0 \cdot 35)$. The significant interval effect in the "off" state resulted from the unwarned (S1-S2 interval of $0 \mathrm{~ms}$ ) being significantly longer than the other four intervals $(p<0.05)$, with no differences ( $p>0.05)$ between the warned conditions (S1-S2 of 200-3200 ms).

\section{Use of advance "movement parameter"} information

Reaction times in the two partially cued conditions did not differ either on or off medication ( $p>0.05)$. Therefore the mean of the two partially cued conditions was used in further analyses. To assess the effects of advance information on RT, for the 200 to $3200 \mathrm{~ms} \mathrm{S1-S} 2$ intervals, the uncued, mean of partially cued, and fully cued CRT conditions on and off medication were compared (fig 5). A three-way repeated measures ANOVA was performed, with condition, interval and medication status as the variables. No significant effects were present for medication status $(F(1,7)<1, \mathrm{p}=0.99)$, the medication status by condition (multivariate $F(2,6)=2 \cdot 9$, $\mathrm{p}=0.13)$, the medication status by interval (multivariate $F(3,5)=0.91, \mathrm{p}=0.49$ ), or the medication status by condition by interval interactions (multivariate $F(2,6)=0.81$, $p=0.65)$. As expected, the main effect of condition $F(2,14)=12 \cdot 6, \mathrm{p}=0.001)$ and interval $(F(3,21)=8, \mathrm{p}=0.001)$ were significant as was the condition by interval interaction $(F(2,14)=4 \cdot 5, \mathrm{p}=0.03)$.

A further repeated measures ANOVA was carried out to determine the relationship between the fully cued four-choice CRT and the SRT (fig 6). The medication status by condition $(F(1,7=0.38, \mathrm{p}=0.56)$ and the

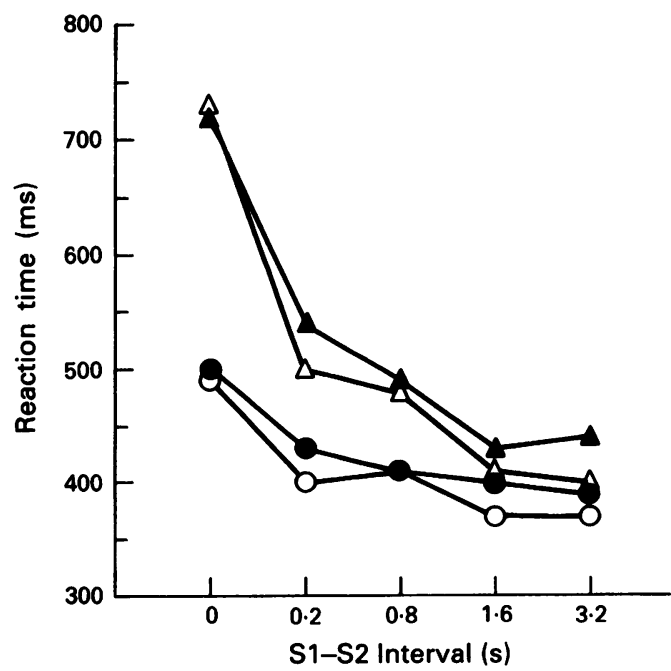

Figure 6 The mean RTs of the patients with Parkinson's disease across the five S1-S2 intervals in the SRT (circles) and the fully cued CRT (triangles) conditions, when tested on (unfilled symbols) and off (filled symbols) medication.

Figure 5 The mean RTs of the patients with Parkinson's disease across the 200-3200 ms S1-S2 intervals in the uncued (circles), mean of two partially cued (triangles) and fully cued (squares) CRT conditions when tested on (unfilled symbols) and off (filled symbols) medication.

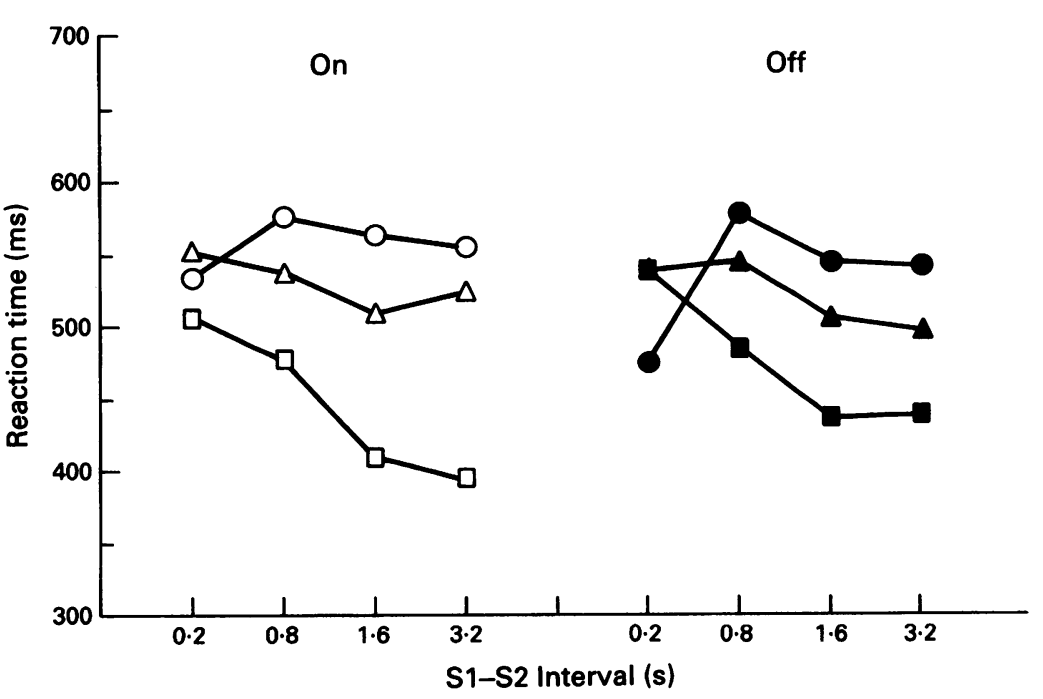


medication status by interval (multivariate $F(3,5)=2 \cdot 3, \mathrm{p}=0 \cdot 19)$ and the medication status by condition by interval (multivariate $F(3,5)=1.6, \mathrm{p}=0.31$ ) interactions, which were of interest, were not significant. Therefore, the S1-S2 interval at which fully cued four-choice CRT became equivalent to SRT was not different in the on and off states.

\section{Movement time}

Across all conditions, movement time was slower after levodopa withdrawal than when tested on medication. In the random block SRT condition, the mean movement time was $332 \mathrm{~ms}$ (SD 71) when tested on and $389 \mathrm{~ms}$ (SD 65) off medication. When tested on medication, mean movement time in the uncued, partially cued, and fully cued CRT conditions was respectively 444 (SD 103), 463 (SD 91), and 450 (SD 119) ms. After levodopa withdrawal, the average movement times in the uncued, partially, and fully cued CRT conditions was respectively 469 (SD 84), 489 (SD 88) and 498 (SD 79) $\mathrm{ms}$. When the movement times in the SRT, the uncued, partially or fully cued CRT conditions were compared on and off medication, none of the effects were significant (medication status: $F(1,7)=1 \cdot 2, \mathrm{p}=0.32)$; condition: multivariate $F(4,4)=3.9, \mathrm{p}=0.11 ;$ medication status by condition: multivariate $F(4,4)=1 \cdot 6$, $\mathrm{p}=0.33$ ).

\section{Errors}

Across the conditions, the number of anticipation, long and decision errors made when the eight Parkinson's disease patients were tested on medication were compared with those made in a drug reduced state. The only difference was that the number of anticipation errors in the fully cued four choice CRT condition was less off than on medication (Wilcoxon $Z=2 \cdot 2, \mathrm{p}=0.03$ ). Given the number of comparisons that were made, however, little value can be attached to a single significant result.

\section{Discussion}

In summary, the eight patients were more severely disabled by Parkinson's disease in the "drug reduced" state than when tested on medication. In general, however, this greater disability was not reflected in their performance on the RT tasks. The results will be discussed in terms of the influence of dopamine depletion on motor readiness and motor programming. Before doing so, however, it is important to note that the "on" versus "off" results are not confounded by differential effects of withdrawal of dopaminergic on MT, fatigue effects or the pattern of errors. The patients' MTs in the SRT or CRT tasks were not different when tested on or off medication, nor were the patients susceptible to greater fatigue in the drug reduced state than when tested on medication. Across all conditions, the number of errors were generally low and remained unaltered after withdrawal of dopaminergic medication.
Does withdrawal of dopaminergic medication affect motor readiness?

Two aspects of motor readiness were examined. First, the speeding of RT by a warning signal and, second, the ability to develop an anticipatory set when the onset of the imperative stimulus was temporarily predictable because of the fixed S1-S2 intervals.

Patients benefited from a warning signal presented before the imperative stimulus both on and off medication. In general, the effects of a warning signal was similar in the two medication states as shown by the fact that both on and off medication (a) warned RTs at all four S1-S2 intervals were faster than unwarned RT and (b) a warning signal $200 \mathrm{~ms}$ before $S 2$ reduced reaction times the most. With regard to the effects of medication on the ability to develop an anticipatory set in the fixed block SRT condition, the only difference was that when tested off medication, the patients did not benefit from the prior knowledge that the imperative stimulus would be unwarned (that is, an S1-S2 interval of $0 \mathrm{~ms}$ ). In other words, when off medication, the patients appear to need the external trigger of a warning signal to generate a state of readiness to respond.

Brown and Robbins ${ }^{10}$ assessed the impact of unilateral striatal dopamine depletion on RT in rats. In a CRT task, in which a variable preparation interval preceded the imperative stimulus, the rats showed pre-operatively a decrease in RT as the preparatory interval lengthened. The longer the interval, the greater the probability that the stimulus would be presented and the greater the animals' response readiness. Dopamine depletion abolished this interval dependent speeding of RT. It was concluded that striatal dopamine depletion altered that aspect of motor readiness which depends on use of endogenous cues for increasing general readiness to respond across a preparatory interval as the onset of the imperative stimulus increased in probability. In contrast to Brown and Robbins ${ }^{19}$ findings, in the present study, withdrawal of dopaminergic medication did not alter the general alerting or activating effect of a warning signal presented at various intervals before the imperative stimulus.

\section{Does withdrawal of dopaminergic medication affect motor programming?}

This question can be addressed from two aspects of the data. Firstly, the effects of medication state on SRT versus CRT. Secondly, its effects on the use of advance information for pre-programming of motor responses.

Medication state had no significant effect on either the unwarned SRT (S1-S2 interval of $0 \mathrm{~ms}$ ) or the unwarned and uncued CRT. In the SRT condition, advance information about the required response is implicitly available to the subject and pre-programming is therefore possible. There is no evidence that medication state affected the use of such information for pre-programming of responses. Furthermore, the fact that both on and off medication, RTs 
in the partially and fully cued CRT conditions were faster than in the uncued CRT suggests that advance movement parameter information was used to pre-programme responses in both medication states. Therefore the use of explicit advance information in the pre-cued CRT tasks was also unaffected by medication status. In addition, both on and off medication the pre-cued four-choice CRT was equivalent to the true SRT condition only with the $3200 \mathrm{~ms}$ S1-S2 interval. In conclusion, the use of advance movement parameter information was in no way affected by withdrawal of dopaminergic medication.

The present results agree with the findings of two of the comparative SRT/CRT studies, those of Girotti et $a l^{5}$ and Pullman et al, ${ }^{9}$ who also found that dopamine levels do not influence either SRT or CRT. The results also confirm the conclusion of Rafal et al ${ }^{11}$ that dopaminergic medication does not affect that stage of processing which reflects use of advance information to pre-programme a motor response. The present results also agree with the demonstration by Brown and Robbins ${ }^{19}$ that, in the rat, unilateral striatal dopamine depletion resulted in global slowing of RT but did not differentially or selectively impair the use of advance information in a precued CRT task or in their true CRT task described earlier. The difference between the present results and those of Rafal et $a^{11}$ and Brown and Robbins ${ }^{19}$ is that the significant global slowing of RT resulting from dopamine depletion obtained in these studies was not observed in this study.

Pullman $e t ~ a l^{7}$ found that increasing levodopa infusion levels significantly reduced directional CRT but not SRT. To explain this, it was suggested that SRT and CRT may be respectively mediated by the motor and complex loops differentiated by Alexander et al. ${ }^{20}$ It was further suggested that the performance on SRT tasks may be independent of striatal dopaminergic mechanisms and instead be modulated by noradrenergic mechanisms affecting the functions of the supplementary motor area. However, Brown and Robbins ${ }^{19}$ have noted that, as the supplementary motor area forms a functional loop with the putamen, with the latter area showing the greatest degree of dopamine depletion in Parkinson's disease, ${ }^{12}$ the explanation of Pullman $e t a l^{7}$ that SRT does not depend on striatal dopamine is difficult to accept. Furthermore, this proposal by Pullman et $a l^{7}$ leaves unexplained why SRT has been found to be so greatly slowed in Parkinson's disease in a large number of studies $^{2122}$ including their own. ${ }^{79}$ It should also be noted that the selective effect of levodopa infusion level obtained in the 1988 study of Pullman et $a l^{7}$ was not replicated in their later study ${ }^{9}$ where levodopa infusion level had no effect on either SRT or CRT.

Two alternative explanations of the nonsignificant effects of medication state on RT in this study can be considered. The first explanation is in terms of the procedural aspects of the present study: the fixed order of "on-off" testing and the length of time during which dopaminergic medication was withdrawn. The second explanation would relate to the role of striatal dopaminergic mechanisms in SRT and CRT.

The first procedural point relates to the fact that all patients were tested on medication first and after an average of 2.8 months on a second occasion in a "drug-reduced" state. It could be argued that this fixed order of testing might partly account for the fact that medication state had no effect on SRT, CRT or the use of advance information. Worringham and Stelmach $^{23}$ reported that, with practice, patients with Parkinson's disease showed improvement on SRT but not CRT, whereas the controls only improved on CRT. In the present study, compared with the first testing on medication, the patients' uncued CRT was faster when tested on the second occasion in the "drug reduced" state (see figs 1 and 2). From Worringham and Stelmach's data ${ }^{23}$ an even greater speeding up as a result of practice would be expected for SRT. It is possible that in the present study, withdrawal of dopaminergic medication would have slowed SRT in our patients but, because of speeding up of RT with practice from the first to the second testing occasion, the net effect is the observed one of no significant change. However, there is no evidence to suggest that the practice effects observed by Worringham and Stelmach ${ }^{23}$ within sessions and across two consecutive days of testing, can be generalised to our study with a mean of 2.8 months between the two testing occasions.

The second procedural point concerns the question of whether the mean withdrawal period of 14.4 hours was sufficient to significantly deplete brain dopamine levels. It is possible that withdrawal of medication for a longer period would have produced significant increases in RT, MT and differential effects on SRT and CRT. Despite the fact that gross mobility and severity of symptomatology, as indicated by the Webster ratings, was affected by levodopa withdrawal, a finger lifting RT and a simple ballistic movement required for moving from a "home" to a "response" key (MT) was not significantly prolonged. The fact that the patients were clearly more disabled after drug withdrawal, however, suggests that significant depletion of striatal dopamine had occurred compared with the medicated condition. This may imply that different thresholds exist for the effects of levodopa withdrawal on RT and MT and general physical symptomatology, to become apparent.

Such an explanation in terms of possible threshold related effects of levodopa on RT and MT contingent on the complexity of the movement involved is consistent with the findings of Benecke et al. ${ }^{24}$ The aim of their study was to compare the effects of levodopa withdrawal on simple versus complex movements. The results showed that, after levodopa administration, MTs of both simple and complex movements were improved, although the improvement in complex movements was more marked. The procedures of this latter study differed in several major respects from those of 
the present investigation. Firstly, Benecke and colleagues tested patients off medication and then on medication within the same testing session. In the present study, the patients were tested on medication on a first occasion and then off medication on a second occasion, with the testing occasions being separated by an average of 2.8 months. Secondly, even when performed in isolation, the simple movements of Benecke et al $\left(30^{\circ}\right.$ elbow flexion and $30 \mathrm{~N}$ hand squeeze) were qualitatively different from the single joint finger lift RT and simple ballistic jump MT of the present study. This is an important procedural difference in light of the fact that Benecke et al noted that "administration of levodopa to patients who had been withdrawn from therapy for the preceding 12-18 hours also produced a more striking improvement in performance of complex combinations of two movements (generally more than $20 \%$ ) than it did in single movements executed alone (about 10\%)." In light of the differentially greater effect of levodopa on complex than simple movements in the study of Benecke et al, ${ }^{24}$ the lack of significant effect of levodopa withdrawal on the much simpler RT and MTs of the present study are consistent with the proposal that the effects of levodopa may be threshold related, with differentially greater effects contingent on increasing complexity of movement.

A second and alternative explanation for the absence of on-off effects on SRT, CRT and use of advance information needs to be considered. Namely, that performance on these tasks may not be solely mediated by striatal dopamine levels. This is also a feasible explanation of the present results and is not in conflict with previous studies ${ }^{925}$ and our own, earlier finding ${ }^{18}$ that patients with Parkinson's disease are slower than age-matched controls on both SRT and CRT tasks and require longer to use advance information to pre-programme responses. It is possible that slowing of SRT and CRT are a non-specific consequence of brain damage or neurological disease rather than specific to Parkinson's disease and its concomitant dopaminergic deficiency.

Support for the proposal that the slowing of RT may be a non-specific feature of any form of brain damage is available from the results of a number of studies. Prolonged SRT or CRT, or both, compared with normal controls have been reported for epilepsy sufferers, ${ }^{26}$ patients with Alzheimer's disease, ${ }^{27}$ and various samples of cases of head injury. ${ }^{2829}$ Furthermore, slowing of RT is also observed in psychiatric conditions such as depression and schizophrenia, ${ }^{30}$ as well as in normal ageing. ${ }^{31}$ This evidence would suggest that global RT deficits may be a non-specific sequelae of brain disease and even normal ageing. Furthermore, although selective impairment of SRT ${ }^{72}$ and the converse pattern of selective impairment of CRT in Parkinson's disease ${ }^{32} 33$ both have supportive evidence, neither pattern has universal support and neither pattern is specific to Parkinson's disease. The inability to benefit from advance information in reaction time tasks (that is, SRT deficits) has been reported for patients with frontal lobe damage,${ }^{34}$ lesions of the supplementary area ${ }^{35}$ and Alzheimer's disease sufferers. ${ }^{27}$ The impairment of CRT relative to SRT has also been found for other patients with brain damage. ${ }^{2829}$ The question of the extent to which the slowness shown by patients with Parkinson's disease on SRT and CRT tasks and in the use of advance information is specific to this disorder needs to be addressed in future comparative studies including both patients with other disorders of the basal ganglia as well as those with neurological diseases sparing the basal ganglia.

This work was supported by a grant from the Wellcome Trust.

1 Hornykiewicz O. Brain neurotransmitter changes in parkinson's disease. In Marsden $C D$ and Fahn S, Eds. Movement disorders 1, Butterworth: London, 1982: Movement

2 Garnett ES, Nahmias C, Firnau G. Central dopaminergic pathways in hemiparkinsonism examined by positron emission tomography. Can f Neurol Sci 1984;11:174-9.

3 Velasco F, Velasco M. A quantitative evaluation of the effects of L-dopa on Parkinson's disease. Neuropharmacology 1973;12:80-99.

4 Heilman KM, Bowers D, Watson RT, Greer M. Reaction time in Parkinson's disease. Arch Neurol 1976;33: $139-40$.

5 Girotti F, Carella F, Grassi MP, Soliveri P, Marano R, Caraceni T. Motor and cognitive performances of Parkin-
sonian patients in the on and off phases of the disease. $f$ Sonian patients in the on and off phases of the
Neurol Neurosurg Psychiatry 1986;49:657-60.

6 Bloxham CA, Dick DJ, Moor M. Reaction times and attention in Parkinson's disease. $\mathcal{F}$ Neurol Neurosurg Psychiatry 1987;50:1178-83.

7 Pullman SL, Watts RL, Juncos JL, Chase TN, Sanes JN. Dopaminergic effects on simple and choice reaction time performance in Parkinson's disease. Neurology 1988;38: 249-54.

8 Starkstein S, Esteguy M, Berthier ML, Garcia H, Leiguarda $R$. Evoked potentials, reaction time and cognitive performance in on and off phases of Parkinson's disease. $f$ Neurol Neurosurg Psychiatry 1989;52:338-40.

9 Pullman SL, Watts RL, Juncos JL, Sanes JN. Movement amplitude choice reaction time performance in Parkinamplitude choice reaction time performance in ParkinSon's disease may be independent of dopamine
f Neurol Neurosurg Psychiatry 1990;53:279-83.

10 Teravainen H, Calne D. Quantitative assessment of Parkinsonian deficits. In Rinne UK, Klinger M, Stamm G, Eds. Parkinson's disease-current progress, problems and management. Amsterdam: Elsevier/North-Holland Biomedical Press, 1980:145-164.

11 Rafal RD, Posner MI, Walker JA, Friedrich FJ. Cognition and the basa ganglia. Separating mental and motor components of performance in Parkinson's disease. Brain 1984;107:1083-94.

12 Viallet F, Trouche E, Beaubaton D, Legallet E, Khalil $R$. Visual feedback and motor performance in human and animal basal ganglia dysfunction. In Shneider JS, Libby TI, Eds. Basal ganglia and behavior. Toronto: Huber, 1987:71-82.

13 Montgomery EB, Nuessen J. The movement speed/accuracy operator in Parkinson's disease. Neurology 1990;40: 269-72.

14 Webster DD. Clinical analysis of the disability in Parkinson's disease. Modern Treatment 1968;5:257-82.

15 Hoehn MM, Yahr MD. Parkinsonism: onset, progression and mortality. Neurology 1967;17:427-42.

16 Beck AT, Ward CH, Mendelson M, Mock JE, Erbaugh JK. An inventory for measuring depression. Arch Gen Psychiatry 1961;4:561-71.

17 Folstein MF, Folstein SE, McHugh PR. "Mini-Mental State": A practical method for grading the cognitive state of patients for the clinician. F Psychiatr Res 1975; 12:189-98.

18 Jahanshahi M, Brown RG, Marsden CD. Simple and choice reaction time and the use of advance information for motor preparation in Parkinson's disease. Brain 1992; 115:539-64.

19 Brown VJ, Robbins TW. Simple and choice reaction time performance following unilateral striatal dopamine depletion in the rat. Brain 1991;114:513-25.

20 Alexander GE et al. Parallel organization of functionally segregated circuits linking basal ganglia and cortex. Ann Rev Neurosci 1986;9:337-81.

21 Bloxham CA, Mindell TA, Frith CD. Initiation and execution of predictable and unpredictable movements in Parkinson's disease. Brain 1984;107:371-84.

22 Sheridan MR, Flowers KA, Hurrell J. Programming and execution of movement in Parkinson's disease. Brain 1987;110:1247-71.

23 Worringham CJ, Stelmach GE. Practice effects on the preprogramming of discrete movements in Parkinson's disease. I Neurol Neurosurg Psychiatry 1990;53:702-4.

24 Benecke R, Rothwell JC, Dick JPR, Day BL, Marsden CD 
Simple and complex movements off and on treatment in patients with Parkinson's disease. $\mathcal{f}$ Neurol Neurosurg Psychiatry 1987;50:296-303.

25 Stelmach GE, Worringham CJ, Strand EA. Movement preparation in Parkinson's disease. The use of advance preparation in Parkinson's disease. The

26 Bruhn P, Parsons OA. Reaction time variability in epileptic and brain-damaged patients. Cortex 1977;13:373-84.

27 Gordon B, Carson K. The basis for choice reaction tim slowing in Alzheimer's disease. Brain and Cognition 1990;13:148-66.

28 Miller E. Simple and choice reaction time following severe head injury. Cortex 1976;6:121-7.

29 van Zomeren AH, Deelman BG. Long-term recovery of visual reaction time after closed head injury. $f$ Neurol Neurosurg Psychiatry 1978;41:452-7.

30 King HE. Psychomotor aspects of mental disease. Cambridge:
Harvard University Press.

31 Wilkinson RT, Allison S. Age and simple reaction time: Decade differences for 5,325 subjects. $₹$ Gerontol Psychol Sci 1989;44:29-35.

32 Weisendanger M, Schneider P, Villoz JP. Electromyographic analysis of a rapid volitional movement. $A \mathcal{F}$ Phys $\mathrm{Med}$ 969;48:17-24

33 Reid WGJ, Broe GA, Hely A et al. The neuropsychology of de novo patients with idiopathic Parkinson's disease: the effects of age of onset. Intern $\mathcal{f}$ Neurosci 1989;48: 205-17.

34 Alivisatos B, Milner B. Effects of frontal or temporal lobectomy on the use of advance information in a choice reaction time task. Neuropsychologica 1989;27:495-503.

35 Verfaellie M, Heilman KM. Response preparation and response inhibition after lesions of the medial frontal lobe. Arch Neurol 1987;44:1265-71. 